\title{
Analysis of the perceptions of wine consumers toward environmental approaches: Support for the management of environmental strategy
}

\author{
R. Symoneaux, D. Ugalde, and F. Jourjon ${ }^{\mathrm{a}}$ \\ USC CLUSTER ESA-INRA, 49000 Angers, France
}

\begin{abstract}
For several years now, the protection of the environment has become a priority for public authorities and the agricultural sectors. On one hand, this has led, in Europe and in the world, to the challenge of modifying or redesigning farming itineraries. On the other hand, it has also caused a multiplication of environmental approaches and environmental product labeling across all sectors. Several studies clearly show that French consumers are increasingly sensitive to environmental information and are in favor of mandatory environmental labeling. These elements tend to encourage agricultural value chains to develop environmental communication strategies as a key factor of differentiation and competitiveness. However, few studies address the joint evaluation of environmental and quality labeling of products under a quality sign, especially for those with a strong image of AOC ("Appellation d'Origine Contrôlé" or "Controlled Origin Denomination") such as wine. This approach is even more important since the publication of the 2016 decree giving to AOC wines the possibility to integrate agro-ecological measures into their specifications.

Through the analysis of consumers' representations and perceptions regarding environmental approaches, the objective of the work is to provide professionals in the wine sector i) objective elements to support changing viticulture practices at the individual farm level and ensuring their commercial valorization among consumers ii) information enabling an AOC union to define an environmental strategy and support integration of agro ecological measures in its specifications.

The work conducted by USC GRAPPE since 2014, across the French territory with more than 3,700 consumers, has identified a number of trends. First, there is a clear general lack of awareness among consumers regarding the majority of the existing environmental labels besides the AB logo ("Agriculture Biologique" or "Organic Agriculture"), which is the only one they known. The results obtained show different consumers' perception of the link between a "wine's category" and its "environmentally friendly production". Overall, AOC wines are perceived as significantly more respectful of the environment compared to the IGP ("Indication Geographique Protégée" "Protected Geographical Indication") wines which at the same time, are better perceived than the VDT ("Vins de France" or "Wines of France"). In addition, the reputation of an AOC can have an influence on the perception of its environmental respect. The results also confirm the importance of integrating consumers' segmentation according to their level of involvement with the product versus the involvement with the environment.

Finally, wine consumers' representation of the environmental impact of different practices throughout the wine bottle production process, was addressed through a qualitative and quantitative approach and confirms the importance given to the phase "vineyard production". This work provides insights into consumers' perceptions of the possible links between the signs of quality and an environmentally-friendly production. These elements, coupled with an eco-design based work, can identify the most relevant practices to be changed from an environmental and consumer point of view.
\end{abstract}

\section{Introduction}

For the past few years, agricultural sectors have been at the heart of the environmental protection problematic. The public authorities make it a priority. In France, the law $n^{\circ} 2009-967$ stipulates that regarding on consumer products "consumers must have sincere, objective and complete environmental information related to the overall characteristics of the product/packaging couple". Indeed, studies show willingness from consumers to have access to the product's assessment of environmental performance, in particular in the form of a comprehensible and universal

a e-mail: f.jourjon@groupe-esa.com labeling [1-3]. However, for the wine industry, studies have also shown that the majority of consumers « do not look for additional information about the environment when they choose a wine and are not interested in an environmental label » [4].

To date, no work has been done on the impact of wine awareness on consumers' perception of the environment. This question is important in the case of a high valueadded agricultural product, offering a very wide range of different products due to their label, reputation, price and organoleptic or environmental quality. No constraints concerning environmental respect are included in the specifications of the AOCs. However, it seems that this 
label appears in the eyes of consumers, as a promise of a more or less strong environmental respect depending on their environmental involvement [4].

During the act of purchase in the supermarket, consumers choose a wine mainly according to the vineyard and the appellation [5]. The majority of studies on wine consumption segment the population according to the consumption frequency [6]. Jourjon et al, showed the importance of segmenting according to the level of involvement in the world of wine. At the same time, other studies have focused on understanding the implications of environmental awareness among consumers [7-17].

This work presents the synthesis of different studies conducted on the representation of environmental dimensions by French consumers. It allows to respond to some answers around five themes: i) their knowledge of environmental labels ii) the influence of their level of wine and environmental involvement on wine environmental perception iii) the interaction between an AOC and its environmental representation iv) the interaction between the environmental label and the perception of the wine quality), v) their level of knowledge and environmental representation of the different viticulture and oenological practices. Finally, this work gives clues to wine professionals and in particular the AOC unions, on how to use these results in managing their environmental strategy.

\section{Materials and methods}

The work was based both on qualitative studies like focus group and quantitative surveys [18]. The focus groups were composed of 10 to 12 people, lasted 2 hours and were organized based on a 15 questions interview guide. All of these round tables were transcribed and their content analyzed.

Four survey questionnaires were administered between 2012 and 2016. They were organized around the five axes presented above. The questions related to wine consumers' involvement and were taken from previous studies [4-18]. Issues related to the consumers' environmental involvement were based on the model proposed by Schlegelmilch [19]. According to this model, consumers' interest in the environment can be assessed through its eco-purchasing behavior, environmental knowledge and attitudes, recycling behavior, and the importance given to environmental policy initiatives.

For the AOC sub-section, two AOCs per wine-growing region were chosen: one very renowned, and another less known and corresponding to a generic name (e.g. for Bordeaux: "Saint Emilion" and "Bordeaux"). The choice of the AOCs and the regions were made from the work of $[20,21]$ on the notoriety of French AOCs in France.

The order of the questions was randomized before sending the questionnaire but remained the same for all of them. The answers were collected via the internet. The questionnaires were sent by mail using several databases provided by the "Vignerons Indépendants de France" (VIF), the association of Rural Families and, the School of Agriculture of Angers (ESA). It was also diffused in the "Ethical Consumption" and "60 Million Consumers" forums and personal networks. 3700 complete cumulative responses were obtained for all surveys. The segmentation of the sample according to wine and environmental involvement was done by a calculation notes' sum. The

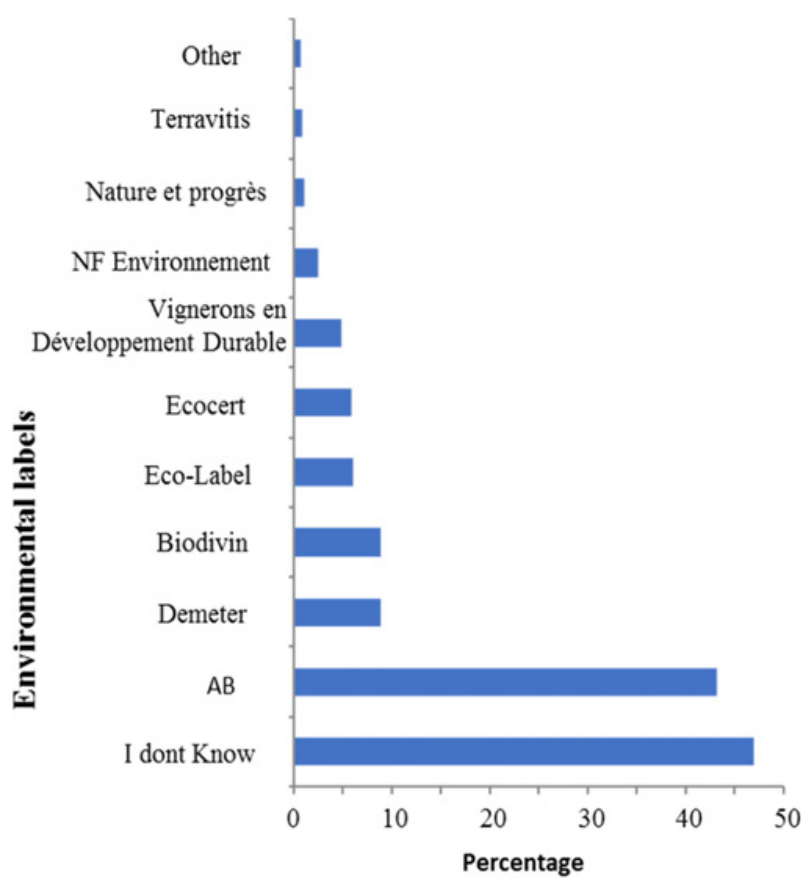

Figure 1. Spontaneous knowledge of environmental logos by wine consumers.

sample was then divided into three classes, to have three levels of involvement (Low, Medium, and High): V1, V2, V3 (Wine involvement) and E1, E2, E3 (Environmental Involvement). Data processing was performed using flat sorting, cross sorting, Principal Component Analysis (PCA) and Variance Analysis (ANOVA). The analysis of the results systematically includes a verification of the influence of wine and environmental involvement on the ratings of the different questions. These tests were carried out using the statistical software XLSTAT 2014 and Question Data.

\section{Results}

\subsection{Consumers' knowledge of environmental labels}

Consumers have had difficulties in citing quality signs in the broad sense, mentioning very few logos related to the environment showing their lack of knowledge on the subject. The Fig. 1 present the segmentation of the surveyed population in two categories: $45 \%$ could not spontaneously mention an environmental label and $45 \%$ cited the AB logo.

For the consumers interviewed during the round tables, the environment was clearly not a criterion of purchase. Indeed, there has been a lack of confidence and skepticism towards the organic sector. However, for many participants, the AOC represents an environmental guarantee because it implies a notion of control.

\subsection{Interaction between the level of involvement and environmental perception}

The influence of wine and environmental involvement on the perception of wine environmental respect has been studied (Fig. 2). Looking at the consumer' segmentation according to wine implication, the people least involved 


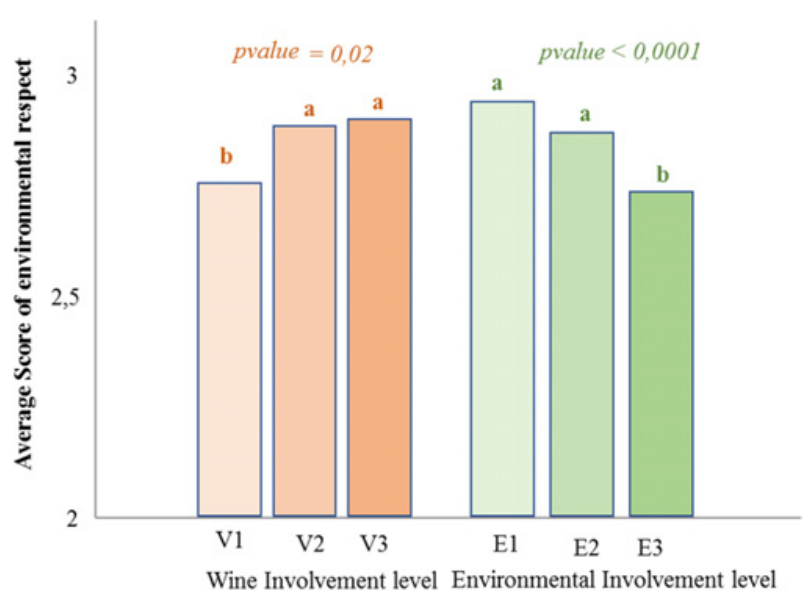

Figure 2. Average score of the environmental perception of wine for each class in our sample.

in wine (V1) considered it to be less respectful of the environment than people more involved in wine (V2 and $\mathrm{V} 3$ ). So, the more involved a person was in the world of wine, the more he/she had a favorable perception of the environmental respect of the wine production. Concerning the environmental implication, the people most involved in the environment noted more severely the wine environmental respect compared to the least involved people (E1 and E2).

\subsection{Interaction between $A O C$ and environmental representation}

Consumers were asked about their perception of environmental respect for three categories of wine: AOC (Appellation d' Origine Contrôlée), IGP (Protected Geographical Indication) and VDT (Vin de France). Significant differences were observed between each category (Fig. 3). AOC wines had on average, a higher score compared to the IGP wines, which themselves had a higher score compared to the VDT. In this study, consumers considered that the production of an AOC wine was more environmentally friendly than one of an IGP wine. In the same way, the production of an IGP wine was considered more respectful than one of a VDT (Fig. 4). These results are independent of the level of wine and environmental involvement. A person not knowing wine (V1) or not involved in the environment (E1) will have noted in the same order, the environmental respect of the AOC, IGP and VDT wines as a person very involved (V3).

People were also surveyed on the environmental representation of 5 French wine regions. The environmental implication was crossed with the perceptions' notes of the regional production environmental respect. As before, overall, the more a person was involved in the environment, the lower the perception of environmental respect was. Alsace is better rated than other regions. Bordeaux, on another hand, is rated by all groups, especially by the most involved (E3), as the least respectful of the environment.

The same type of crossed analysis was made between wine involvement and the evaluation of the regions' environmental respect. The more a person was involved in wine, the more she/he had a favorable perception of the regions' environmental respect. Whether for wine or

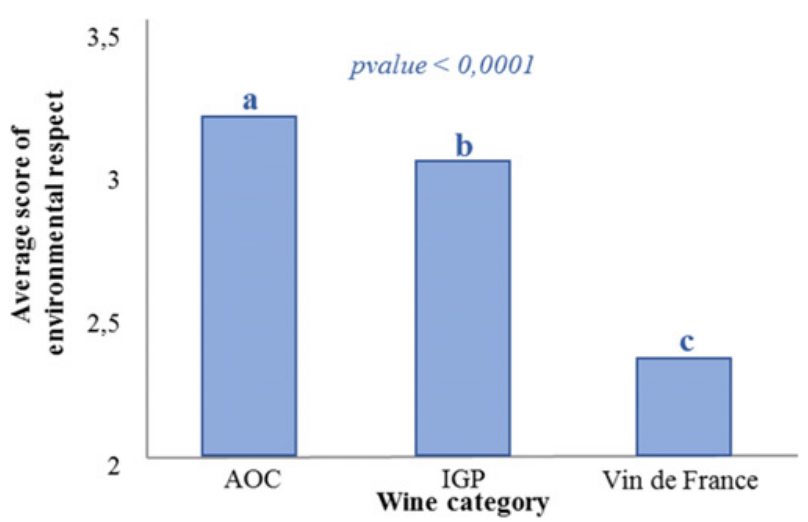

Figure 3. Average score of the perception of environmental respect for each category of wine.

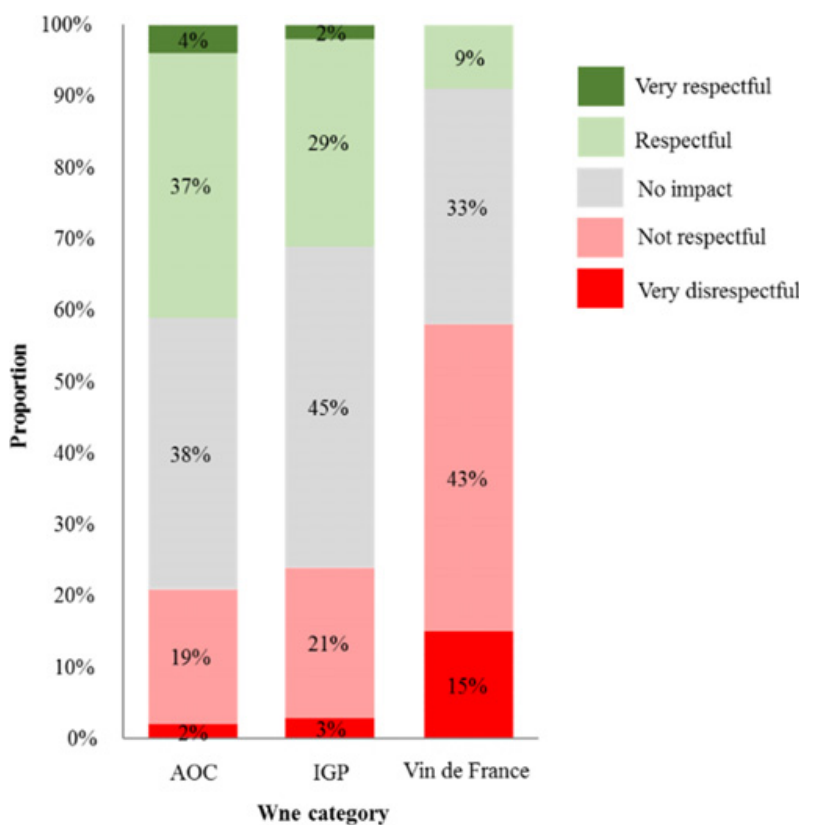

Figure 4. Proportion of each type of response in the average rating of wine categories.

environmental involvement, Bordeaux is considered in our studies as the least environmentally friendly region by all classes and, especially by the most involved (E3 and V3). Burgundy is also judged, but to a lesser extent, more severely by these two classes, while the Rhone Valley has an identical score for the classes V2 and V3.

The perception of the environmental respect of the ten AOC selected within the 5 regions, led to two scenarios. For Saint Emilion versus Bordeaux and Châteauneuf du Pape vs. Rhône Valley, the AOC with a very high reputation was perceived as more environmentally friendly than the AOC with a lower reputation. For Alsace, the Loire Valley and Burgundy, there was no significant difference between the two AOCs. Thus, the perception of the environmental respect of an AOC seemed to depend on the level of awareness of this AOC and, on the overall perception of the wine region. Actually, it was rather the region that influenced more consumers on their perception of an AOC environmental respect. 


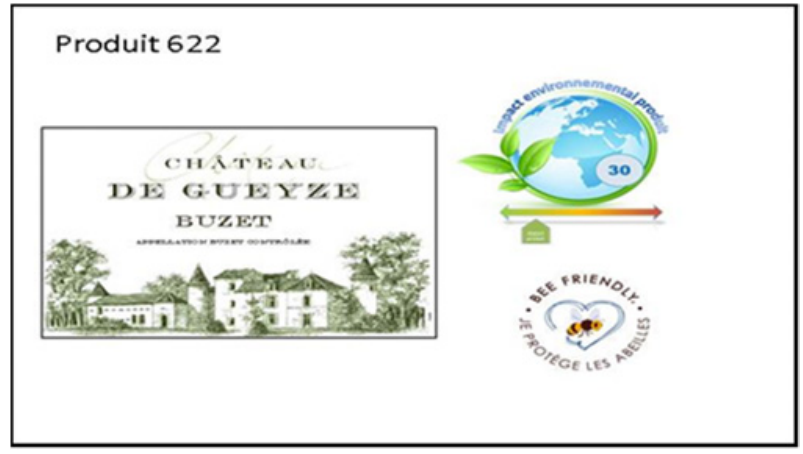

Figure 5. Projected image on the screen before tasting.

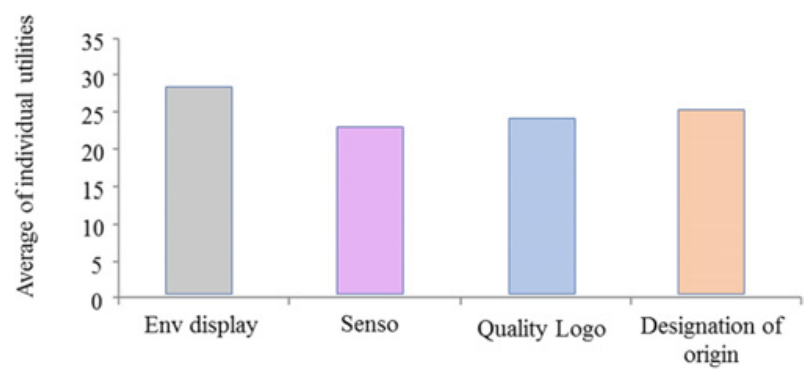

Figure 6. Impact of the display type on overall wine appreciation.

\subsection{Interaction between AOC, environmental representation and quality perception of wines}

In addition to the previous surveys, a joint analysis made it possible to evaluate the weight of an environmental display in the appreciation of a wine in relation to other attributes (sensory, appellation, qualitative logos, provenance). Given the elements available in the bibliography, the following were chosen : the sensory attributes (fruity wine vs. more astringent wine), the environmental performance (Good performance vs. Bad performance), the qualitative logos (Bee Friendly vs. Gold Medal), and the appellation (Buzet vs. Bordeaux). To present the environmental performance, a dummy display was created after discussion with a representative of the Ministry of the Environment. It was also inspired from the projects currently being discussed within the ADEME-AFNOR platform related to the product's environmental labeling. The tasters savored 16 products in two sessions. While tasting each glass of wine, an image (Fig. 5) was projected onto their screen to indicate the characteristics of the product. They were then asked to rate their appreciation.

The results of this joint analysis clearly showed a very positive impact of the environmental label on the appreciation of wine. Products with a label indicating better performance were significantly more appreciated (Fig. 6). However, utility percentages show that all variables are important to consumers (Fig. 7). The small differences in individual utility averages for the other factors indicate a segmentation of consumers for these attributes. Consumers are consensual for environmental labeling. On the other hand, for each modality tested in parallel, they are more shared.

In addition, it's interesting to note that consumers do not have the same sensitivity to environmental labeling. Of course, the vast majority of consumers have more appreciated wines with the best environmental performance, but this difference is much more marked for

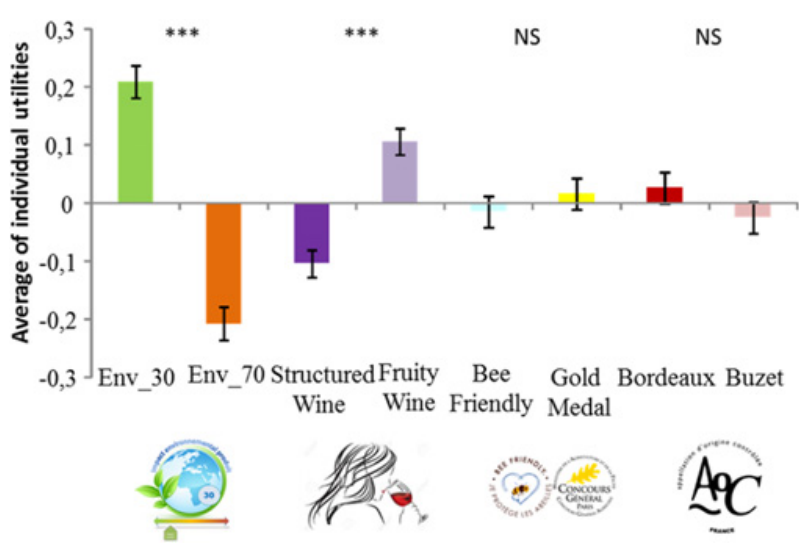

Figure 7. Differences in individual utility means for the other studied factors.

consumers who are more involved in the environment. In this study, wine involvement has no impact on the sensitivity to environmental labeling.

\subsection{Knowledge and environmental representation of viticulture and oenological practices}

Two round tables were held in 2019 with a total of 19 people, wine consumers of all ages and gender, living in Angers and its periphery.

The round tables were organized in several stages. First, consumers were asked to identify the different phases of wine production. All participants were able to identify the stage of production in the vineyard. A very large majority identified wine making, packaging, marketing, and consumption. Half of them integrated the collection and treatment of post-consumer waste. However, only a few identified the phases upstream of the vineyard production, that is, the planting of vine plants or the production of agricultural inputs, machinery, among others.

Following the identification of the different stages, they were asked to classify them according to their positive or negative effect on the environment. There was no consensus on the stage "production in the vineyard", "packaging" and "the collection and treatment of post consumption waste". Nevertheless, "distribution" and "marketing" were judged to have a negative effect, especially because of the transportation phases. Vinification, on the other hand, has been judged to have a positive effect on the environment.

A brainstorming session then allowed us to delve deeper into the perceived positive effects of wine production. Culture and identity, hedonic and festive attributes, the positive effect on health (if the wine is drunk with moderation), the influence on landscapes' aesthetics and, the economic and social contributions to local economies were cited.

Secondly, they were asked to name wine "practices", or concrete ways to act of winemakers that have an impact on the environment. The most evoked ideas concerned in the first place, the phytosanitary treatments related to the producer's production method (organic farming, reasoned, "zero phyto", biodynamic or conventional). Tillage has also been strongly evoked ("soil preparation, feeding the land, land development"). As a negative effect of 
the practices, participants cited chemical treatments, soil pollution, ecosystem modification, and impacts on human health.

Finally, they were asked to evaluate the understanding of a list of viticulture practices and their positive or negative perception of the impact of these practices on the environment. Overall, consumers understood the statements and were able to provide an opinion on the impact of the practice. The practices perceived mainly as having a negative impact on the environment were: the use of imported stakes, the use of mineral fertilizers, the use of phytosanitary products CMR (carcinogenic, mutagenic, reprotoxic or altering human fertility) and the chemical weeding.

Concerning practices with a positive effect on the environment, consumers' opinions were quite divided. The installation of nest boxes (artificial nest that is suspended from the trees to facilitate the reproduction of birds) was the only practice being perceived mainly as having a positive effect.

These results show the need to analyze more in detail the representations of consumers on viticulture practices. A quantitative survey of 1000 French consumers representing wine national consumption is being administered. It will enable stakeholders in the sector to better understand consumers' perceptions and expectations and to better target environmental communication strategies.

\section{Conclusions}

Faced with the diversity of labels and environmental approaches many opportunities are opening up to the wine industry to communicate on its efforts to reduce environmental impacts.

In all the studies conducted (individual interviews, focus groups, quantitative studies, etc.), it appears that the implementation of new logos or information must meet the need for trust expressed by consumers. These steps should therefore be accompanied by a guarantee of traceability, transparency, and controls. This issue of environmental information will be complex to manage since consumers want information in the form of a simple and synthetic global indicator and, transparency on how the product was made. Therefore, communication efforts will have to be very important to convince them. Indeed, in spite of a profusion of initiatives, we note that a majority of consumers do not know the existing environmental logos, except for the organic farming logo. This shows the way to go to educate consumers about this environmental information.

This study confirms again the relevance of consumer segmentation vis-à-vis of their involvement in the world of wine and/or the environment, especially when we are interested in specific issues such as the perception of the environmental approaches. The more involved people are in the world of wine, the more they view wine production processes as environmentally friendly. Conversely, the more involved consumers are in the environment, the more they consider wine production processes to be less respectful of the environment and, the more they are generally demanding of environmental information and labels.

These results do not call into question the relevance of a display or an environmental label but, once again, account for the awareness and communication needed to convince and change the behavior of a majority of consumers.

Finally, our results showed that consumers perceive significant differences between wine quality signs regarding environmental respect during the production processes. The AOC does appear to have been perceived as more respectful of the environment, followed closely by the IGP. In the mind of the consumer, the "Vin de France" was perceived as the least environmentally friendly. Beyond these three factors influencing environmental perception (wine involvement, environmental involvement and wine category), we noticed that the reputation of an AOC could have an influence on the perception of its environmental respect. Indeed, in the minds of consumers and in the case of Bordeaux and the Rhone Valley, AOCs with a very strong reputation were perceived to be more environmentally friendly than AOCs with a medium reputation. In the other regions (Val de Loire, Alsace, Burgundy), no significant differences were observed between the two AOC levels. The impact of the wine region therefore, seemed more important than the reputation of an AOC for the consumers' perception of environmental respect. Even if the environmental messages do not seem a priority to wine consumers during their purchase for AOC wines, the environmental image of the regions is an important stake and can impact the notoriety of the regions ... Each year examples of media campaigns pointing out environmental topics prove it.

In a context of increasing power of organic movements and societal sensitivity to environmental issues, it may be interesting for wine producing areas to integrate this ecological dimension into their specifications as authorized by the 2016 decree. In their communication strategy they could also be attentive to the environmental regulations implemented on a national or regional level. A reinforcement of the dialogue and the interactions between the actors of the viticulture profession, consumers, residents and citizens, in the framework of participative approaches, could be relevant in order to consolidate the confidence acquired in the case of an AOC.

\section{References}

[1] Ernst \& Young (2009, Juillet) Pistes pour un étiquetage environnemental lisible et efficace Résultat d'enquête consommateurs

[2] Enquete Ethicity (2011, Mars) Les Français et la consommation responsable - On se prend en main http://www.blogethicity.net/share/docs/

[3] Enquete Ethicity (2012, Mars) Les Français et la consommation responsable - Le plaisir de la simplicité http://www.blog-ethicity.net/share/

[4] F. Jourjon, R. Symoneaux, Comment le niveau d'implication des consommateurs de vin modifie leurs perceptions et attentes d'un affichage environnemental du vin Bulletin OIV (2013)

[5] Interloire, Enquête consommateurs - Choisir son vin, les six critères clefs [en ligne] http://www . vitinet.com/vigne_vin/article/choisir-sonvin-les-six-criteres-clefs-(2013)

[6] F. Brugieire, Pratiques culturales sur vignes et pratiques œnologiques : connaissances et opinion des Français. Vinifhlor-Infos Vins et cidres, $n^{\circ} 160$, Feìvrier 2009, pp. 71-80 (2009) 
[7] N. Barber, C. Taylor, S. Strick, Int. J. Wine Res. 1, 59 (2009)

[8] C. Najar, I. Zaiem, Revue Libanaise de Gestion et d'Économie 3, 1 (2010)

[9] I. Vermeir, W. Verbeke, J. Agricult. Environ. Ethics 19, 169 (2006)

[10] Demarque, Christophe, MONACO, Grégory Lo, APOSTOLIDIS, Thémis, et al. Socialisation, perspectives temporelles et implication personnelle : une étude dans le champ de l'environnement. Cahiers Internationaux de Psychologie Sociale (2011), vol. 92 , p. $353-369$

[11] C. Xiao, R.E. Dunlap, Social Sci. Q. 88, 471 (2007)

[12] G. Laurent, J.N. Kapferer, J. Mark. Res. (JMR) 22, 1 (1985)

[13] N. Michaelidou, S. Dibb, Mark. Rev. vol. 8, 83 (2008)

[14] S. Mueller, H. Remaud, Are Australian wine consumers becoming more environmentally conscious? Robustness of latent preference segments over time,
Thèse de doctorat (University of Auckland business School, 2010)

[15] L. Sirieix, Consumer perceptions of eco-friendly vs. conventional wines in Australia, Thèse de doctorat (University of Auckland business school, 2010)

[16] H. Stolz, O. Schmid, Consumer attitudes and expectations of organic wine (2008)

[17] J. Zaichkowsky, J. Consum. Res. 12, 341 (1985)

[18] F. Jourjon, R. Symoneaux, Perception des consommateurs et intérêt d'un étiquetage environnemental pour les productions de vins d'AOP. Revue des œnologues et des techniques vitivinicoles et œnologiques (2013), vol. 40, no. 148 , p. 53

[19] B. Schlegelmilch, G. Bohlen, A. Diamantopoulos, Eur. J. Mark. 30, 35 (1996)

[20] J. Cassagnes (2013, Septembre 13), Vins de Loire Une notoriété en hausse auprès des consommateurs français. Consulté le Mars 10, 2014, sur Viti-net

[21] L. Gotti (2012, Décembre 27), Le Top 5 des appellations. Consulté le Mars 10, 2014, sur 365 jours en Bourgogne, Le blog de Laurent Gotti 